CITE AS: Weiler, B., Moyle, B.D., Wolf, I.D., de Bie, K. and Torland, M. (2016) Assessing the Efficacy of Communication Interventions for Shifting Public Perceptions of Park Benefits. Journal of Travel Research. DOI: 10.1177/0047287516646472

\title{
Assessing the Efficacy of Communication Interventions for Shifting Public Perceptions of Park Benefits
}

\begin{abstract}
One way national parks can sustain their societal relevance and ensure ongoing political and community support is through conscious and deliberate repositioning. This study investigates the potential for psychologically repositioning national parks using persuasive communication designed to shift public perceptions of the benefits of visitor experiences in parks. The experimental communication interventions were selected to target benefits where gaps were identified between the perceptions of park managers and the parks' constituent publics. Using a pre-post design on 1,055 respondents split evenly across two Australian states, the experiment revealed that the website and the video used as interventions were highly effective at improving public perceptions of park benefits. This was attributed to the persuasiveness of the website and the video, which respondents rated as having positive valence, as highly vivid and as credible. This research provides theoretically informed insights into the application of persuasive communication theory to psychologically reposition national parks.
\end{abstract}

Keywords: Benefit, National park, Intervention, Reposition, Persuasion, Public perception 


\section{Introduction}

National parks are clearly defined geographic spaces, managed through legal or other effective means, to conserve nature for future generations (Eagles and McCool 2002; Hall and Frost 2009). National parks not only play a critical role in maintaining biodiversity and in some cases shielding endemic species from extinction; they also offer people the opportunity to access space to experience and benefit from the natural environment. In many countries, visits to national parks make up a very significant component of the tourism "product". Yet in some instances visitation levels to national parks have plateaued or are in decline (Pergams and Zaradic 2008; Balmford et al. 2009).

There is some evidence to suggest that maintaining visitor levels by providing satisfying experiences in national parks is a way of garnishing support for park management (MacArthur 1994). Competition for funding leisure and other public services has generated concern that a decline in national park visitation levels could lead to a reduction in support for the provision of visitor services and facilities, and for the existence of parks in general (Weiler, Moore, and Moyle 2013). As with any product or service, the public needs to hold positive perceptions of the benefits of parks to be motivated to consume (visit) and support parks in perpetuity (Crompton 2008). Thus, managers need to be able to gauge public perceptions and, where needed, take action to promote positive perceptions of park benefits (Hughes and Carlsen 2008). Until recently, however, such action has been driven by managers' intuitions about public perceptions rather than by theory and research.

To build support for parks among constituent publics there has been a growth in studies that seek to quantify and communicate the full range of park values, including personal and societal benefits associated with visiting parks (Eagles 2014). Empirical research has demonstrated that visiting parks can lead to distinctive physical, mental and social health benefits (Kaczynski and Henderson 2007). However, the majority of previous research examining public and community perceptions of these benefits has focused on urban parks, or on individual national parks (e.g. Ho et al. 2005; Hung and Crompton 2006; Kemperman and Timmermans 2006; Ulrich and Addoms 1981; Gulzar et al. 2010; Leahy et al. 2009). Moreover, little is known about how well the values and expectations of managers regarding visitor experiences in parks align with those of users and other stakeholders. This is made more challenging by the fact that each park will have a distinctive set of assets, stakeholders and experiences. Thus the application of theory to inform research and benefit alignment may look different from park to park. Perhaps partly due to these challenges, there has been a dearth of research examining the utility of communication interventions for shifting public perceptions of specific park benefits. Consequently, the aim of the present research is to examine the efficacy of communication interventions for shifting public perceptions of the benefits of providing visitor experiences in national parks. As such, this manuscript builds on previous phases of a larger study as reported in Moyle, Weiler and Moore (2014), Torland et al. (2015), and Moyle and Weiler (2016), and integrates literature on market positioning and repositioning, persuasive communication and park benefits. Particular attention is paid to the contribution of mental imagery and credibility to the persuasive potential of the two communication interventions selected.

The core contribution this study seeks to make is to provide empirical support for the predominantly conceptual literature that has argued for repositioning of parks and leisure services (Crompton 2000; 2009). In particular, the study demonstrates how public perceptions and thus the market position of an agency's suite of national parks and potentially any one individual park can be shifted via theoretically-informed communication interventions. On a practical level, the paper offers a benchmark of current perceptions in two Australian states together with a set of tools that can be 
used by park managers seeking to assess and monitor the on-going impact of communication interventions on public perceptions.

\section{Literature}

The main bodies of literature that inform the constructs and relationships investigated in this study are marketing (positioning and repositioning), social psychology (persuasive communication) and park management (benefits-based management). Brief overviews of each are presented to illustrate their applications in the present study.

\section{Market Positioning of National Parks}

The concept of positioning is at the core of marketing (Kotler 2000) and refers to a company's or organization's efforts to make its brand or products distinctive, in the minds of its customers and relative to the competition. While this can be achieved in part through manipulating product features, creating an image of an organization's products or services is central to the concept of positioning (Kacynski and Crompton 2004a). Positioning has come relatively late to public sector organizations, and thus has lacked the conceptual clarity needed to underpin its application in contexts such as national park planning and management. What is clear, however, is that market positioning plays a key role in the public's propensity to visit national parks and to support park management agencies and associated conservation activities (Crompton 2009). Notwithstanding the complexity of positioning parks in comparison to other products and services, market positioning is acknowledged as one of several tools critical to building vital constituent support for conservation and safeguarding visitor experiences in nature (Blain, Levy, and Ritchie 2005; Weber and Anderson 2010).

Park management agencies are responsible for providing access to and encouraging visitor experiences as part of their mandate (Rodger, Taplin, and Moore 2015). Public perceptions of the benefits of these park experiences play an important role in the market position held by national park management agencies (Kaczynski and Crompton 2004b). What is largely unknown is the extent to which the public's perceptions of the benefits of visiting national parks align with the aspirations of managers. As with any product or service, mismatches or gaps between product offerings and consumer perceptions, in this case the benefits that park managers desire to project and the public's perceptions of those benefits, may pose threats to the supplier (the park management agency) and the product (the visitor experience) (Davies and Chun 2002; Vercic and Vercic 2007). Thus, identifying and closing gaps between the desired image (the benefits that park managers desire to project) and the perceived image (the public's perceptions of benefits) is critical for optimizing the market position of national parks.

The use of benefits as a tool to manipulate and shift the market position of parks has been proposed for some time (Crompton 1993). Despite this, extant literature is primarily conceptual, with a dearth of empirical research to complement existing foundations. Notable exceptions include the work of Kaczynski and Crompton (2004b) who developed the Parks and Recreation Repositioning Scale (PARRS), an operational tool for determining the optimum position of parks and recreation departments. However, PARRS was developed in a North American context primarily for urban parks and recreation agencies, rather than focusing on national parks. We return to the subject of an instrument for measuring perceptions of park benefits in the final section of this review of literature.

Repositioning, similar to its parent construct of positioning, has received little attention in national park research (Pike 2004). Psychological repositioning is one of several types of repositioning which, in a park management context, involves manipulating public perceptions about 
the benefits that parks can offer to better align with the position desired by park managers (Crompton 2009). This is often less costly in the short term than, for example, real repositioning, which involves the development of new services or the restructuring of existing services so that they better contribute to delivering desired benefits (Crompton 2009). As such, psychological repositioning needs to draw heavily on communication designed to manipulate the image of a product or service (Rettie, Burcheel, and Riley 2012). To our knowledge, the science that underpins psychological repositioning via persuasive communication has not been developed and tested in the context of national parks.

\section{Persuasive communication}

Persuasive communication seeks to "bring about a willing change in the attitudes, beliefs, opinions or behavior of others" (Davies et al. 1981, 298). While it is generally acknowledged that change seldom comes about instantaneously (Robbins et al. 2003), strategic marketing communication is nonetheless designed to persuade audiences to think, feel or do something new or different (De Janasz et al. 2006). Persuasive communication is not new to park management, and many examples of core principles being applied to influence visitor behavior in and around national parks can be found (Manfredo 1992; Steckenreuter and Wolf 2013). However, these have been primarily within the context of nature and heritage interpretation (e.g. Ballantyne, Packer and Hughes 2009; Brown, Ham, and Hughes 2010), with researchers drawing on persuasive communication theories such as the Elaboration Likelihood Model (Petty and Cacioppo 1986) to elicit pro-environmental attitudes and behaviors since at least the late 1980s (Roggenbuck 1992; Kim and Weiler 2013).

Within the large body of literature focused on how communication can be made more persuasive (cf. Cialdini 2001; Sparks, Perkins, and Buckley 2013), the two constructs of credibility and mental imagery have been cited as integral for repositioning in a park management context (Weiler et al. 2014). Mental imagery, defined as "a mode of cognition involving the activation of perceptual knowledge stored in memory" (Miller, Hadjimarcou, and Miciak 2000, cited in Lee and Gretzel 2012,2), is important because it tends to mediate an individual's attitudinal and behavioral responses to communication. A number of studies (Miller and Stoica (2004), Lee, Gretzel and Law (2010), Lee and Gretzel (2012) and Walter, Sparks and Herington (2007) make a compelling case for the importance of mental imagery in tourism communication. Credibility is identified as the first essential element of effective persuasion (De Janasz et al. 2006). The establishment of credibility stems from personal characteristics such as expertise, trustworthiness, composure and positive impression. Furthermore, credibility can include the degree to which followers perceive someone as honest, competent, and able to inspire (Robbins et al. 2003). The perception of the source of communication as being credible is also central to persuasion and tourism communication (Pornpitakpan 2004; Veasna, Wu \& Huang 2013). This suggests that employing elements of credibility and mental imagery into a communication intervention will enhance its potential to persuade, or in the case of the present study, its potential to shift perceptions of the benefits of visitor experiences in national parks. The operationalization of credibility and mental imagery in the present study is discussed in the methods section of the paper.

\section{Benefits of Tourism, Leisure and Recreation in Parks}

Up to this point, we have provided an overview of literature on market positioning, repositioning and persuasive communication which, as will be seen in the methods section, underpin the study's conceptualization and the design of the communication interventions used in the present study. We now return to the desired effect of these interventions: improvement in the perceptions that the public holds regarding the benefits of visiting national parks. 
The benefits of tourism, leisure and recreation have been a key area of scholarly attention since the 1970s (see Driver and Tocher 1970). The benefits of leisure and recreation are defined as an improvement in condition or gain to an individual, to a group, to society, or to another entity (Driver, Brown, and Peterson 1991). Since the seminal work of Driver and colleagues, benefits have been examined extensively, especially within the context of parks (Manning 2011). Findings from previous research on benefits suggest a core group of experiential benefits that stem from time spent visiting national parks and include, for example, learning, participating in outdoor recreation activities, family togetherness, and solitude (Anderson et al. 2000; Crilley, Weber, and Taplin 2012).

As a consequence of the increased recognition of the importance of benefits, Benefits Based Management (BBM) began to receive considerable attention in the leisure and recreation literature (Driver, Brown, and Peterson 1991). BBM suggests that if visitors can be persuaded to visit and participate in particular activities in appropriate settings they have the potential to not only achieve their desired tourism or recreation experience, but also to accrue higher-order benefits, on-site and off-site as well as short-term and long-term (Weber and Anderson 2010). Benefits documented in the literature include connecting with nature and heritage, strengthening family ties and improving mental and physical health (Weber et al. 2009). Outcomes-Focused Management (OFM), the most recent iteration of $\mathrm{BBM}$, recognizes that the benefits of providing visitor experiences in parks accrue not only at a personal (experiential and higher-order) level, but also at a broader societal (community-wide) level (Manning 2011). For example, providing visitor experiences in parks are thought to help conserve and protect nature, heritage and culture, reduce the cost of health care and enhance community well-being (Maller et al. 2006).

Public perceptions of benefits and social values are now used by many national park management agencies to gauge public support for parks (van Riper et al. 2012). Toward this end, an earlier stage of the present study mined the list of the benefits of leisure created and updated by Driver and colleagues $(1991 ; 2008)$ and used the findings from interviews with senior park management officials to develop a set of benefits of visiting parks that is relevant to Australian park managers and the Australian public (see Table 1). An earlier stage of the present research (described in Methods) found that park managers aspire to deliver visitors the benefits presented in Table 1, although managers will certainly vary in their ranking of importance or desirability of specific benefits (Moyle, Weiler and Moore 2014). The public's perceptions of these benefits constitute the suite of outcome variables in the present study.

Based on this literature, the present study examines the efficacy of communication interventions in shifting public perceptions of benefits and thus psychologically repositioning visitor experiences in national parks. Further, it explores the extent to which mental imagery and credibility are associated with shifts in the perceptions of benefits. The overarching aim of the research is to generate theoretically-informed insights into how park management agencies can reposition visitor experiences in parks.

[Insert Table 1 here]

\section{Method}

\section{Study Context}

This paper builds on the findings of two earlier stages of a three-year study that included New South Wales (NSW) and Victoria and their respective park management agencies - National Parks \& Wildlife Service (NPWS) and Parks Victoria (PV). PV is the largest public manager of tourism 
assets in Australia, attracting almost 35 million visits a year to 45 national parks in the state of Victoria (Newspoll 2013). NPWS is responsible for managing over 200 national parks in NSW and while the entire estate managed by the agency attracted 35.5 million visits in 2012, six national parks received almost $40 \%$ of all visits (Roy Morgan Research 2013).

In the first stage of the overall study, an extensive review of literature, a content analysis of corporate documents, and interviews with 27 senior park managers produced a set of 39 benefits that park managers desire to project to their constituent publics, presented in Table 1. The second stage measured the aspirations of park managers with respect to each of these benefits, the perceptions of the public (state-wide surveys in each state) regarding the benefits of visiting parks, and the congruence or lack thereof (gap) in the perceptions of these two groups of 'stakeholders' (managers and the public) across the 39 benefit items. Results of the state-wide surveys of perceptions of national parks that provided the impetus for the present study revealed that the relative importance of benefits did not differ between the two respondent groups, although in some cases the perceptions of residents of NSW were significantly more positive than Victorian residents (Moyle and Weiler 2013). Collectively the actual visitor experiences available in national parks in the two states are also comparable.

However, of particular relevance to the present paper are the gaps between managers and the public in the two states, as these informed key decisions for stage three. In NSW, gaps were notable between senior managers' and the public's perceptions of benefits relating to heritage and culture (learning about nature, culture and heritage; connecting with heritage; connecting with culture; conservation of heritage; conservation of culture). In Victoria there were significant gaps between senior managers and the public's perceptions of benefits relating to health and well-being (access to natural experiences; improving quality of life; achieving mental and physical health benefits; reducing the cost of health care; increasing community well-being). Consequently, a decision was made in consultation with NPWS (NSW) and PV (Victoria) to administer a communication intervention in each state targeted at shifting the public's perceptions of heritage and culture benefits (NSW) and health and well-being benefits (Victoria), to see if such communication could narrow the gap between the perceptions of senior managers and the public, and thus psychologically reposition the provision of visitor experiences in national parks.

\section{Intervention Design}

The decision was made to undertake a field-based assessment of the impacts of communication interventions on public perceptions of the benefits of visitor experiences in national parks. There would certainly be merit in addressing the research problem using a pure experimental approach where variations between the communication interventions are eliminated and the effects of individual factors are tested in isolation, but there are also limitations to these kinds of studies, which necessarily take place in controlled and artificial environments. As argued by Wells (2014), reliable and valid measures and comprehensive understanding are most likely to emerge from research experiments that artificially manipulate variables together with field-based studies that measure the effectiveness of real world communications, and from "constructive criticism and mutually supportive interaction between the two camps" (Wells 2014: iv).

Field-based research is used widely for measuring message effectiveness in advertising (Zou, 2005) but also in other contexts such as conservation psychology (Weinstein et al. 2015) and tourism (Tubb 2003). There is thus a sound basis for undertaking a field-based study, and we return to the bigger picture of progressing dialogue and understanding from the findings of this study in the conclusion of the paper. 
Core principles of persuasion informed the selection of communication interventions for this experiment. The criteria included the purpose of the communication (designed to convey benefits to parks visitors), its ability to target key benefits, its persuasive potential (including the use of credibility and mental imagery), the ease with which it could be administered, and its potential for further use by the park agency. Following a review of existing marketing collateral in each agency, two experimental communication interventions were identified, one for each of the two state-based agencies.

For the NSW sample, excerpts from the recently redeveloped website were used as the intervention to strategically target (i.e. to improve) perceptions relating to heritage and culture benefits of visiting parks (learning about nature, culture and heritage (benefit \#11); connecting with heritage (\#15); connecting with culture (\#16); conservation of culture (\#25); conservation of heritage (\#26) - see Table 1). NPWS's website is one of the agency's key tools for communicating the benefits of and encouraging visitation to national parks. At the time the study was conducted the website was being redesigned to engage with the public in a new and exciting way. The actual intervention consisted of a narrated PowerPoint presentation of six-and-a-half minutes depicting selected segments (21 slides) of this "new" NPWS website. The focus was on one suburban park, as well as a second remote park, both of which offer varied heritage/culture based experiences and nature-based experiences, as well as protection of rich heritage resources. The website exhibited several elements of contemporary website design, including the use of narrative text (not lists of functional attributes) and pictorial features (Tsai, Chou, and Lai 2010; Lee and Gretzel 2012).

The communication intervention selected for the Victoria sample was a video that targeted the health and well-being benefits of spending time in parks (access to natural experiences (\#1); achieving mental and physical health benefits (\#21 and \#22); improving quality of life (\#24); increasing community well-being (\#32); reducing the cost of health care (\#38) - see Table 1). The three-and-a-half minute promotional video clip, relating to parks managed by PV, communicated the agency's "healthy parks healthy people" (HPHP) theme. This video was produced for a world Healthy Parks Healthy People Congress, and was wide-ranging and evocative in its presentation of the benefits of visiting (and protecting) parks, including video and still photography of people enjoying parks in a variety of ways. It included an upbeat soundtrack and narration with brief cameotype appearances by national park rangers, university researchers and others being interviewed onsite.

Both the website and the video are realistic examples of how each agency communicates with its constituent publics. Both were already in existence, yet neither had been viewed by members of the public participating in the study, saving the need to invest resources (time and money) on the development of communication tools. The development of both the NPWS website and the PV video were informed by marketing communication principles and, in the case of the NPWS website, indepth marketing research to maximize its persuasiveness in conveying the benefits of visiting parks.

\section{Pilot test}

A classroom-based pilot test of the interventions and the pre-post experimental design survey on 68 undergraduate students was undertaken and served several useful purposes. Firstly, the pilot study included a test for priming, that is, to what extent differences between respondents' pre-intervention and post-intervention ratings were simply a reaction to their exposure to and their own recollection of how they responded in the pre-intervention questionnaire. The results of this pilot test strongly supported the notion that any differences between pre- and post-test responses were due to the persuasiveness of the intervention and not priming. Priming effects were not evident for 36 out of the 39 items, and for none of the targeted heritage and culture benefit items (Weiler et al. 2014). As a result, no further tests for priming were included in this study and the researchers proceeded with a 
pre-intervention questionnaire, communication intervention and post-intervention questionnaire administered sequentially without a time gap between them.

Secondly, the pilot study (which surveyed 18-25 year olds in a classroom-based setting) provided some opportunity for testing for construct validity, and concluded that the website content and delivery was deemed by some respondents to be not sufficiently persuasive. This was addressed by shortening the time spent on each webpage, and adding an auditory (Lee \& Gretzel 2012) narration component to improve the intervention. Thirdly, based on response bias and survey administration issues experienced in the pilot, an on-line survey via a panel provider was selected as the best approach for gaining a representative sample of the target population (residents of the states of NSW and Victoria). Finally, open-ended responses in the pilot study pointed to the need for additional measures in the main study to explain why the website was successful. This prompted the addition of items regarding respondents' judgement of persuasive elements of the interventions, discussed in the last subsection of Methods.

\section{Instrument design and sampling}

Following the pilot test, an on-line survey with a pre-post intervention design was administered to a sample of 532 NSW residents, with the NPWS website as the intervention, and 521 VIC residents, with the HPHP video as the intervention. The samples in both states were stratified according to region (targets of 250 urban and 250 regional), gender (250 males; 250 females) and age (200 aged $18-29 ; 100$ aged $30-49 ; 200$ aged 50 or over) to ensure adequate representation of population subgroups. As in previous stages of this study, each benefit item was assessed using a 7-point Likerttype scale from 'very strongly disagree' to 'very strongly agree'. In the on-line survey, respondents were asked to rate each benefit item, then view the communication intervention, and then once again rate each benefit item. Paired-sample t-tests were used to test for statistical significance $(\mathrm{p}<.05)$ in the pre-post results. To account for error associated with the multiple tests and the possibility of receiving a false positive test, as well as the likely correlation between the variables, a bootstrap procedure was applied to adjust the $p$-value. The effect size was estimated using Cohen's $d$ statistic, which is considered small around 0.2 , medium around 0.5 and large at 0.8 or above.

As noted in the literature review, credibility and mental imagery were selected for study as two of many persuasive communication dimensions that can explain the efficacy of a communication intervention. In the absence of scales for measuring source credibility particularly for communicating park benefits, an open-ended question sought feedback on aspects of the intervention that the respondent perceived as "credible" (De Janasz, Dowd, and Schneider 2009) and why. Responses were coded and are reported with respect to frequency of occurrence.

Lee and Gretzel (2012) theorize that the use of narrative, auditory and pictorial features enhances mental imagery processing, which in turn enhances persuasiveness. Noting the merits of identifying the dimensions that contribute to persuasiveness, this research used a validated scale developed by Miller, Hadjimarcou and Miciak (2000). The scale consisted of 17 items to measure the extent to which the intervention used mental imagery across the 4 dimensions of vividness (5 items), valence (5 items), quantity ( 3 items) and modality ( 4 items) (see Table 2 ). To assess the degree to which respondents perceive the intervention as having each of these qualities, 7-point rating scale items were included in the study instrument. A mean rating at or above the mid-point on these four dimensions (4.0) was set as indicating that the dimension positively enhanced persuasive potential. 


\section{Results}

Due to the stratified sampling method there was an even spread between age groups and gender in both states. There were a slightly higher proportion of respondents in NSW who reported that they had visited national parks managed by NPWS during the past 12 months (77.6\%) than respondents in Victoria who reported they had visited national parks managed by PV during the past 12 months $(62.8 \%)$. However, the majority of respondents in both states reported visiting parks infrequently, and a third of NSW respondents and $11 \%$ of Victoria respondents reported visiting parks once a year or less. Table 3 provides a profile of respondents by age, gender, park visitation, and frequency of park visitation by state.

[Insert Table 3 here]

As displayed in Table 4 and 5, pre-intervention means were already positive (above 4.0) for all targeted benefit items. Nonetheless, there was also a statistically significant improvement in the means ratings of all targeted benefits in each state. The positive shifts in perceptions of heritage and culture benefit items (NSW) and health and well-being benefit items (Victoria) were not unexpected, and suggest that communication had at least a short-term effect on improving public perceptions. However, in addition to a shift in the pre-post test results on the targeted benefit items, perceptions of many other benefit items also unexpectedly improved. In NSW, respondents' mean perceptions of 35 out of the 39 benefit items significantly improved following the interventions. In Victoria, respondents' mean perceptions significantly improved for all 39 benefit items included in the instrument.

[Include Table 4 here]

[Include Table 5 here]

Table 6 presents the mean ratings (on a 7-point scale) of NSW and Victoria respondents on each of the mental imagery dimensions of quantity, modality, vividness and valence. For both the website and video, the mean ratings on all four dimensions were all well above the midpoint of 4.0. As can be seen in Table 6, the mean scores of all four dimensions of mental imagery were slightly higher for Victoria than NSW respondents, i.e. the video was rated by respondents as presenting stronger mental imagery than the website. Both interventions were seen to have very high positive valence, that is, the imagery conveyed by the website (5.71) and the video (5.80) was rated by respondents as positive and likeable. Both interventions were also rated as being quite vivid (5.11 for the website and 5.21 for the video), that is, the imagery was sharp and intense. The quantity (number of images) and particularly the modality (use of senses such as taste, sound, and scent) of the mental imagery were rated somewhat lower for both the website and the video. These results may or may 
not explain the slightly higher efficacy of the PV video as compared to the NPWS website in impacting the targeted benefits.

[Insert Table 6 here]

The responses to some of the open-ended questions provide insight into the similarities and differences between the two states with respect to the credibility of the interventions. Table 7 provides a synopsis of selected open-ended responses to the question "Did you see anything in the Parks Victoria video/NPWS website that convinced you that the information you were receiving was credible?" based on a content-analysis and categorizing of the responses.

\section{[Insert Table 7 here]}

As shown in Table 7, the use of photos and other images to depict actual scenery, landscapes and nature found in national parks in the state were identified by $19 \%$ of Victorian respondents and $28 \%$ of NSW respondents as enhancing the credibility of the NPWS website and the PV video. Both the video and the website were considered to be informative and this was seen as adding credibility by $8 \%$ of Victorian respondents (video) and $15 \%$ of NSW respondents (website). Quite a number of respondents (3\% in Victoria and 12\% in NSW) also commented on the video and website as having credibility by virtue of them being affiliated with a government agency. Of particular note, $25 \%$ of Victorian respondents identified the use of park rangers, park uniforms, and other experts as enhancing the credibility of the PV video, and 7\% of Victorian respondents commented on the use of real and everyday people doing activities in parks as important in adding credibility. As shown in Table 7, these last two categories were not evident in the responses to the NPWS website because staff, other experts and real people were not included in the website intervention.

A finding not of direct relevance to the present study was that there were a few significant differences in perceptions of specific benefit items among NSW and VIC community members. Analysis of pre and post intervention means was conducted in relation to a number of sociodemographic variables, including gender, age (under 30 years versus 30 years and over), place of residence (urban versus regional), and park visitation (visitors versus non-visitors). The results suggest that in some cases the interventions were more persuasive with some segments of the public than with others. Generally, however, both interventions were overwhelmingly successful in shifting the perceptions of all segments of the public (Weiler, Moyle and Torland 2013). 


\section{Discussion}

While this study's research design cannot confirm a definitive cause-and-effect relationship between specific persuasive communication elements (mental imagery and credibility) and shifts in the perceived benefits of parks, the change in respondents' perceptions and thus the psychological repositioning of parks is evident. Thus, the findings do support the notion that persuasive communication interventions can be a valuable tool for park management agencies seeking to psychologically reposition visitor experiences in parks. This extends the work of Crompton (2009) who proposed four key strategies for repositioning parks and other leisure services: real, competitive, associative and psychological repositioning. In the context of visitor experiences in parks, real repositioning involves developing new experiences or services or restructuring existing ones so that they better contribute to delivering benefits. For example, to nurture the people-parks relationship for disengaged and/or unaware segments of the public such as young adults, ethnic minorities and new migrants, park management agencies may need to expand their portfolio of nature-based experiences (real repositioning) and reconsider the appropriateness of national parks as places for adventure, social, and spiritual experiences. Associative repositioning focuses on aligning with other organizations that already possess the desired position and acquiring some of this position from the association, in this case, perhaps aligning with commercial providers of nature-based leisure and tourism experiences that the public perceives as providing key benefits. Competitive repositioning refers to altering the public's beliefs about what an agency's competitors deliver with respect to benefits. Psychological repositioning, as illustrated in this study, focuses on shifting the public's beliefs about the benefits which emanate from visitor experiences offered by park agencies, so that they better align with the desired position. As already noted, this may be more expedient and costeffective in the short term, although real repositioning may be more cost-effective in the long term. As Crompton (2009) states, real, associative, psychological and competitive repositioning strategies should be regarded as complementary, not mutually exclusive approaches (Crompton 2009). Thus, to position a park management agency as a provider of visitor experiences that deliver on key benefits, all four strategies should be considered and it is likely that some combination of them need to be pursued simultaneously.

This research provides insights into the potential for communication interventions to achieve psychological repositioning of visitor experiences in parks, one mechanism that can be added to the toolkit of park management agencies seeking to build and maintain relevance. The findings suggest the importance of credibility and mental imagery to psychological repositioning. The use of rangers to enhance the credibility of the information presented may have been a reason why the PV video slightly outperformed the NPWS website, although a more sophisticated research design is required to explore the differences between sources of media. With regard to mental imagery, the results are certainly consistent with Lee and Gretzel (2012) who note the importance of high-quality visual images to mental imagery processing. However, Moyle and Croy (2009) note that with the shift to predominantly on-line sources at the pre-visit information sourcing stage, it is important for park management agencies to use a diverse range of on-line content, with videos, images, text and even narration designed to achieve strategic communication goals. In this research the PV video was highly effective in shifting benefits. However, as already noted, whether the use of video contributed to the better results for the PV intervention (shifting 39 out of 39 benefits) compared to the use of a more static web-based intervention for the NPWS intervention (shifting 35 out of 39 benefits) cannot be discerned from the present study design.

While each of the interventions was designed primarily to focus on a few key benefits, results revealed a considerable spill-over in the persuasiveness of both interventions. The positive shift in 
perceptions of these other benefits is perhaps not surprising, as each of the experimental interventions included a range of visual images, text, and narration that went beyond the targeted benefits. A similar effect was found in the work of Cheng, Woon and Lynes (2011), who noted such effects in previous studies that focus on the promotion of environmentally sustainable behaviors. It may be that the combination of visual, text and narration increases the likelihood of communication interventions shifting both targeted and untargeted benefit items.

The perceptions of the benefits of visitor experiences in parks were significantly impacted as a result of the communication interventions. Although the image of visitor experiences in parks appears to have been significantly positively repositioned by these interventions, findings reveal only a short-term change with further research required to determine the persuasive power of the intervention in the long-term. A six-month follow-up administration of the on-line survey used in this study was originally planned to assess the stability of the shift in perceptions, but had to be abandoned as the sample of respondents could not be accessed. Nonetheless, this study demonstrates the potential of communication interventions, informed by persuasive communication theory, for shifting public perceptions and ultimately for achieving organizational goals and objectives (Hall 2014). Embedding individual communication interventions into a comprehensive communication campaign would further enhance their efficacy. Park management agencies could consider using the instrument employed in this study to monitor the effectiveness of such campaigns on the public's perceptions of the benefits of providing visitor experiences in parks.

\section{Conclusion, Implications and Future Research}

The findings of this study provide new insights into the utility of communication interventions, specifically a targeted video and a customer-focused website, for shifting public perceptions of the benefits of visitor experiences in parks and thus for repositioning national parks. The two interventions were selected for their persuasion potential, in that they had the credibility of being associated with national park management agencies, and they used a combination of text, auditory and pictorial features that are known to enhance mental imagery processing. Both interventions were rated by respondents as being persuasive, and both were successful at positively impacting respondents' perceptions of park benefits, highlighting the importance of embedding elements of persuasion such as credibility and mental imagery into strategic communication interventions. For both the website and the video, the use of a standardized intervention via an on-line survey proved useful in minimizing noise in the experiment.

Unfortunately, the considerable variability between the two interventions prevented the researchers from directly comparing the relative efficacy of the two interventions. The paper's theoretical contribution lies not in trying to compare the two, nor in identifying elements of promotional videos or national park websites that will consistently and reliably impact perceptions and thus psychological positioning across all contexts. Rather, its contribution is to illustrate how consideration of mental imagery and credibility when designing promotional material appears in these cases to have improved their impact. This has implications for other sites and management agencies. From a park management perspective, the findings suggest that both a well-designed website and a high-quality video can indeed impact perceptions of benefits, so either or both of these could be incorporated into a marketing or communication campaign, with a suite of tools developed around specific sets of benefits.

Notwithstanding the potential for management applications, it must be emphasized that, as with any study of this kind, the direct transferability of the specific findings to other park systems and other stakeholder groups needs to be done with caution. Future research should replicate this 
research design at different scales and in different contexts. As such, the concepts, research design and methods used in this study present a solid foundation for the application of persuasive communication theory to the psychological repositioning of public perceptions of the benefits of national parks in other contexts. The instrument employed in this research can be used to determine perceptions of individual parks, and thus can be administered to visitors on-site and to communities adjacent to national parks. Similarly, with some modifications, the study could be adapted to ascertaining the public's perceptions of the benefits of marine parks. The instrument can also be used or adapted to assess the perceptions of other stakeholder groups such as selected interest groups, user/activity groups, politicians, and advisory boards and committees of interest to park agencies.

However, more research is needed to determine "how" best to use communication to psychologically reposition parks. Further experimental (pre-post intervention) research similar to the intervention reported here could be undertaken, with communication interventions custom-designed to shift the perceptions of particular benefit items, and/or to shift the perceptions of specific target groups such as young adults or non-visitors. The real-world field-based nature of this study undertaken with the agencies' actual marketing collateral tested on a cross-section of state residents (rather than, for example, students in a classroom) is certainly a positive, but did limit the scope for isolating and examining the effects of individual communication variables. Future research could experimentally manipulate communication elements, for example, narration vs. non-narration; visuals vs. non-visual; the use vs. non-use of vividness, valence, quantity and modality of mental imagery; and the use vs. non-use of credibility. It appears that collectively these dimensions enhanced persuasiveness, but their separate contributions warrant further research. Other variables not measured in this study such as emotional engagement or the use of normative influences may well prove to be important triggers for shifting perceptions of park benefits. Research on other types of repositioning of visitor experiences in parks, such as competitive, associative and real would complement this study. Finally, there is need for research to determine whether a communication intervention or campaign or even real repositioning (e.g. new experiences in parks) does in fact persuade non-visitors to actually visit parks.

While maintaining support by some segments of the public may be relatively easy, the longterm future of national parks relies on their continued relevance to all its constituent publics. Repositioning can be used as a tool for park management agencies to maintain or reengage the support of past visitors, as well as broaden the appeal of national parks to those segments of the public who are less engaged and aware of their benefits. Understanding the way the public perceives parks and the benefits and values they attribute not only to parks but also to park management agencies, is fundamental to the 'people-park relationship'. Ultimately this is critical for maintaining relevance in a rapidly changing 21 st century society.

\section{Acknowledgements}

This research was funded by an Australian Research Council Linkage Grant, project number: LP100200014. We wish to thank Parks Victoria and the Office of Environment and Heritage (NSW) for their in-kind support and cash contribution to this research. 


\section{References}

Anderson, D. H., R. Nickerson, T. V. Stein, and M. E. Lee. 2000. Planning to provide community and visitor benefits from public lands. Wallingford: CABI Publishing.

Ballantyne, R., J. Packer, and K. Hughes. 2009. "Tourists' support for conservation messages and sustainable management practices in wildlife tourism experiences." Tourism Management 30: 658-664.

Balmford A., J. Beresford, J. Green, R. Naidoo, M. Walpole, and A. Manica. 2009. "A global perspective on trends in nature-based tourism." PLOS Biology 7. doi:10.1371/journal.pbio.1000144.

Blain, C., S. E. Levy, and J. R. B. Ritchie. 2005. "Destination branding: Insights \& practices from destination management organizations.” Journal of Travel Research 43 (May): 328-338.

Brown, T., S. Ham, and M. Hughes. 2010. "Picking up Litter: An application of theory based communication to influence tourist behaviour in protected areas." Journal of Sustainable Tourism 18 (7): 879-900.

Cheng, T., D. K. Woon, and J. K. Lynes. 2011. "The use of message framing in the promotion of environmentally sustainable behaviors." Social Marketing Quarterly 17 (2): 48-62.

Cialdini, R. B. 2001. Influence: Science and practice, 4th edn. Boston: Allyn \& Bacon.

Crilley, G., D. Weber, and R. Taplin. 2012. "Predicting visitor satisfaction in parks: Comparing the value of personal benefit attainment and service levels." Visitor Studies 15 (2): 217-237.

Crompton, J. L. 1993. "Repositioning recreation and park services: An overview.” Trends 30 (4): 2.

Crompton, J. L. 2000. “Repositioning leisure services.” Managing Leisure 5: 65-76.

Crompton, J. L. 2008. "Evolution and implications of a paradigm shift in the marketing of leisure services in the USA." Leisure Studies 27 (2): 181-205.

Crompton, J. L. 2009. "Strategies for implementing repositioning of leisure services." Managing Leisure 14 (2): 87-111.

Davies, G., and R. Chun. 2002. "Gaps between the internal \& external perceptions of the corporate brand." Corporate Reputation Review 5 (2/3): 144-158.

Davies, M. R., K. E. Kreis, J. B. Nutting, and K. E. Tronc. 1981. The Business of communicating. Sydney: McGraw-Hill.

De Janasz, S., G. Wood, L. Gottschalk, K. Dowd, and B. Schneider. 2006. "Persuading Individuals and Audiences." In Communication in Organisations, edited by M. Witsel. North Ryde: McGraw-Hill Custom Publication.

De Janasz, S., K. Dowd, and B. Schneider. 2009. Interpersonal skills in organisations. Sydney: McGraw-Hill. 
Driver, B. 2008. Managing to optimize the beneficial outcomes of recreation. State College, PA: Venture Publishing.

Driver, B. L., P. Brown, and G. L. Peterson. 1991. Benefits of leisure. State College, PA: Venture Publishing.

Driver, B. L., and S. R. Tocher. 1970. "Toward a behavioral interpretation of recreational engagements, with implications for planning." In Elements of outdoor recreation planning, edited by B. L. Driver, and S. R. Tocher. State College, PA: Venture Publishing.

Eagles, P. F. 2014. "Research priorities in park tourism.” Journal of Sustainable Tourism 22 (4): 528-549.

Eagles, P. F. J., and S. F. McCool. 2002. Tourism in national parks and protected areas: Planning and management. Wallingford: CABI.

Godbey, G., and A. Mowen. 2011. "The benefits of physical activity provided by park and recreation services: The scientific evidence." Australasian Parks and Leisure 14 (1): 26-29.

Gulzar, H., N. Muhammad, Y. Adnan, R. Atif, M. A. Khan, and N. Shaheryar. 2010. "Impact of public parks on human life: a case study." Pakistan Journal of Agricultural Sciences 47 (3): $225-230$.

Hall, C. M. 2014. Tourism and social marketing. Abingdon: Routledge.

Hall, C. M., and W. Frost. 2009. "Introduction: The making of the national parks concept." In Tourism and national parks: International perspectives on development, histories and change, edited by W. Frost, and C. M. Hall, 3-15. Abingdon Oxon: Routledge.

Ho, C. H., V. Sasidharan, W. Elmendorf, F. K. Willits, A. Graefe, and G. Godbey. 2005. "Gender and ethnic variations in urban park preferences, visitation, and perceived benefits." Journal of Leisure Research 37 (3): 281-306.

Hughes, M., and J. Carlsen. 2008. "Human-wildlife interaction guidelines in Western Australia." Journal of Ecotourism 7 (2/3): 147-159.

Hung, K., and J. L. Crompton. 2006. "Benefits and constraints associated with the use of an urban park reported by a sample of elderly in Hong Kong." Leisure Studies 25 (3): 291-311

Kaczynski, A. T., and J. L. Crompton. 2004a. "Development of a multi-dimensional scale for implementing positioning in public park and recreation agencies." Journal of Park and Recreation Administration 22 (2): 1-27.

Kaczynski, A. T., and J. L. Crompton. 2004b. "An operational tool for determining the optimum repositioning strategy for leisure service departments." Managing Leisure 9 (3): 127-144.

Kaczynski, A. T., and K. A. Henderson. 2007. "Environmental correlates of physical activity: A review of evidence about parks and recreation.” Leisure Sciences 29 (4): 315-354.

Kemperman, A. D. A. M., and H. J. P. Timmermans. 2006. "Preferences, benefits, and park visits: A latent class segmentation." Tourism Analysis 11 (4): 221-230. 
Kim, A. K., and B. Weiler. 2013. "Visitors' attitudes towards responsible fossil collecting behaviour: An environmental attitude-based segmentation approach." Tourism Management 36: 602612.

Kotler, P. 2000. Marketing Management: Planning, Analysis, Implementation and Control. Englewood-Cliffs, NJ: Prentice-Hall.

Leahy, J., J. M. Shugrue, J. Daigl, and H. Daniel. 2009. "Local and visitor physical activity through media messages: A specialized benefits-based management application at Acadia National Park." Journal of Park and Recreation Administration 27 (3): 59-77.

Lee, W., and U. Gretzel. 2012. "Designing persuasive destination websites: A mental imagery processing perspective." Tourism Management 33: 1270-1280.

Lee, W., U. Gretzel, and R. Law. 2010. "Quasi-trial experiences through sensory information on destination web sites." Journal of Travel Research 49 (3): 310-322.

Maller, C., M. Townsend, A. Pryor, P. Brown, and L. St Leger. 2006. "Healthy nature healthy people: 'Contact with nature' as an upstream health promotion intervention for populations." Health promotion international 21 (1): 45-54.

Manfredo, M., ed. 1992. Influencing human behavior: Theory and applications in recreation, tourism, and natural resources management. Champaign, IL: Sagamore.

Manning, R. E. 2011. Studies in outdoor recreation: Search and research for satisfaction, 3rd edn. Corvallis, OR: Oregon State University Press.

McArthur, S. 1994. "Acknowledging a symbiotic relationship - Better heritage management via better visitor management." Australian Parks and Recreation Journal 30: 12-17.

McCool, S. F., and M. Reilly. 1993. "Benefit segmentation analysis of state park visitor setting preferences and behavior." Journal of Park and Recreation Administration 11 (4): 1-14.

Miller, D. W., J. Hadjimarcou, and A. Miciak. 2000. "A scale for measuring advertisement-evoked mental imagery.” Journal of Marketing Communications 6: 1-20.

Miller, D. W., and M. Stoica. 2004. "Comparing the effects of a photograph versus artistic renditions of a beach scene in a direct-response print ad for a Caribbean resort island: A mental imagery perspective." Journal of Vacation Marketing 10 (1): 11-21.

Moyle, B. D., and W. G. Croy. 2009. "Media in the pre-visit stage of a recreation experience: Port Campbell National Park." Tourism Analysis 14 (2): 199-208.

Moyle, B. D. and B. Weiler. (2013). Community and Park Executives/Directors Perceptions of the Benefits of Parks: A Congruency Analysis. ARC Technical Report, School of Tourism and Hospitality Management, Southern Cross University, Bilinga, Queensland. http://epubs.scu.edu.au/cgi/viewcontent.cgi?article=1505\&amp;context=bus_tourism_pubs

Moyle, B. D., B. Weiler, and S. A. Moore. 2014. "Benefits that matter to managers: An exploratory study of three national park management agencies." Managing Leisure 19 (6): 400-419.

Moyle, B. D. and B. Weiler. 2016. "Revisiting the Importance of Visitation: Public Perceptions of Park Benefits." Tourism and Hospitality Research doi: 10.1177/1467358416638918. In Press. 
Newspoll 2013. Parks Visitation Monitor Quarter 1-4 - 2012/13. Prepared for Parks Victoria, Melbourne 3000.

Pergams, O. R. W., and P. A. Zaradic. 2008. "Evidence for a fundamental and pervasive shift away from nature-based recreation." Proceedings of the National Academy of Sciences, Stanford University, Palo Alto, CA. pp 2295-2300.

Petty, R., and J. Cacioppo. 1986. Communication and persuasion: Central and peripheral routes to attitude change. New York: Springer-Verlag.

Pike, S. 2004. Destination marketing organizations. Oxford: Elsevier.

Pornpitakpan, C. 2004. "The persuasiveness of source credibility: A critical review of five decades of evidence." Journal of Applied Social Psychology 34 (2): 243-281.

Rettie, R., K. Burchell, and D. Riley. 2012. "Normalising green behaviours: A new approach to sustainability marketing." Journal of Marketing Management 28 (3-4): 420-444.

Robbins, S, R. Bergman, I. Stagg, and M. Coulter. 2003. Foundations of management. Sydney: Pearson Education Australia.

Rodger, K., R. H. Taplin, and S. A. Moore. 2015. "Using a randomised experiment to test the causal effect of service quality on visitor satisfaction and loyalty in a remote national park." Tourism Management 50: 172-183.

Roggenbuck, J. 1992. "Use of persuasion to reduce resource impacts and visitor conflicts." In Influencing human behavior: Theory and applications in recreation, tourism and natural resources management, edited by M. Manfredo, 149-208. Champaign, IL: Sagamore.

Roy Morgan Research 2013. Annual visits to PWG managed parks in New South Wales. Final Report 2012. Sydney: Office of Environment and Heritage.

Sparks, B. A., H. E. Perkins, and R. Buckley. 2013. "Online travel reviews as persuasive communication: The effects of content type, source, and certification logos on consumer behavior." Tourism Management 39: 1-9.

Steckenreuter, A., and I. D. Wolf. 2013. "How to use persuasive communication to encourage visitors to pay park user fees." Tourism Management 37: 58-70.

Stein, T. V., and M. E. Lee. 1995. "Managing recreation resources for positive outcomes: An application of benefits-based management." Journal of Park and Recreation Administration 13 (3): 52-70.

Torland, M., B. Weiler, B. Moyle, and I. Wolf. 2015. "Are your ducks in a row? External and internal stakeholder perceptions of the benefits of parks in New South Wales, Australia." Managing Sport and Leisure 20 (4): 211-237. doi:10.1080/23750472.2015.1028428.

Tsai, W-H., W-C. Chou, and C-W. Lai. 2010. "An effective evaluation model and improvement analysis for national park websites: A case study of Taiwan." Tourism Management 31(6): 936-952. 
Tubb, K. N., 2003. "An evaluation of the effectiveness of interpretation within Dartmoor National Park in reaching the goals of sustainable tourism development." Journal of Sustainable Tourism 11(6): 476-498.

Ulrich, R. S., and D. L. Addoms. 1981. "Psychological and recreational benefits of a residential park." Journal of Leisure Research 13: 43-65.

van Riper, C. J., G. T. Kyle, S. G. Sutton, M. Barnes, and B. C. Sherrouse. 2012. "Mapping outdoor recreationists' perceived social values for ecosystem services at Hinchinbrook Island National Park, Australia." Applied Geography 35 (1): 164-173.

Vercic, A. T., and D. Vercic, 2007. "Reputation as matching identities \& images: Extending Davies $\&$ Chun's (2002) research on gaps between the internal \& external perceptions of the corporate brand.” Journal of Marketing Communications 13 (4): 277-290.

Veasna, S., W. Y. Wu, and C. H. Huang. 2013. "The impact of destination source credibility on destination satisfaction: The mediating effects of destination attachment and destination image." Tourism Management 36: 511-526.

Walters, G., B. Sparks, and C. Herington. 2007. "The effectiveness of print advertising stimuli in evoking elaborate consumption visions for potential travelers." Journal of Travel Research 46(1): 24-34.

Weber, D., J. Senior, D. Zanon, and D. Anderson. 2009. "Healthy parks, healthy people: Assessing the benefits gained by Australian park visitors." In Managing to Optimize the Beneficial Outcomes of Recreation, edited by B. Driver, 177-188. State College, PA: Venture Publishing.

Weber, D., and D. Anderson. 2010. "Contact with nature: Recreation experience preferences in Australian parks.” Annals of Leisure Research 13 (1/2): 46-69.

Weiler, B., S. A. Moore, and B. D. Moyle. 2013. "Building and sustaining support for National Parks in the 21st century: Why and how to save the National Park experience from extinction." Journal of Park and Recreation Administration 31 (2): 110-126.

Weiler, B., B. D. Moyle, and M. Torland, 2013. “Testing Trial Interventions Designed to Shift Community Perceptions of the Benefits of Parks." ARC Stage 3 Technical Report, School of Tourism and Hospitality Management, Southern Cross University, Bilinga, Queensland. http://epubs.scu.edu.au/cgi/viewcontent.cgi?article=1506\&amp;context=bus_tourism_pubs

Weiler, B., B. Moyle, M. Torland, I. Wolf, and M. Witsel, 2014. "Lessons Learnt from Pilot-Testing an Experimental Communication Intervention: Generation Y and Park Benefits." Paper presented at CAUTHE 2014 Tourism and Hospitality in the Contemporary World: Trends, Changes and Complexity, Brisbane, Australia. February $10-13 .$.

Wells, W. D. 2014. Measuring advertising effectiveness. New York: Psychology Press.

Weinstein, N., M. Rogerson, J. Moreton, , A. Balmford, , and R. B. Bradbury. 2015. "Conserving nature out of fear or knowledge? Using threatening versus connecting messages to generate support for environmental causes." Journal for Nature Conservation 26: 49-55.

Zou, S. 2005. "Contributions to international advertising research: An as assessment of the literature between 1990 and 2002." Journal of Advertising 34 (1): 99-110. 
Table 1. Personal and Societal Benefits of Visiting National Parks.

\begin{tabular}{|c|c|c|}
\hline $\begin{array}{l}\text { Personal experiential benefits of } \\
\text { visiting national parks: }\end{array}$ & $\begin{array}{l}\text { Personal higher-order benefits of } \\
\text { visiting national parks: }\end{array}$ & $\begin{array}{l}\text { Societal / community-wide benefits } \\
\text { of visiting national parks: }\end{array}$ \\
\hline 1. Accessing natural experiences & 13. Appreciate biodiversity & 25. Conservation of culture \\
\hline 2. Escaping urban environments & 14. Appreciate scenic beauty & 26. Conservation of heritage \\
\hline 3. Being in a comfortable and safe & 15. Connect with heritage & 27. Generation of employmer \\
\hline Dla & 16. Connect with culture & 28. Improved flood management \\
\hline 4. Relaxing and unwinding & 17. Connect with nature & 29. Improved fire management \\
\hline 5. Finding peace and solitude & 18. Connect with spiritual side & 30. Increased business investment \\
\hline $\begin{array}{l}\text { 6. Participating in outdoor recreation } \\
\text { activities }\end{array}$ & $\begin{array}{l}\text { 19. Strengthen social networks } \\
\text { 20. Strengthen family ties }\end{array}$ & $\begin{array}{l}\text { 31. Increased tourism } \\
\text { 32. Increased community well-being }\end{array}$ \\
\hline 7. Socializing with friends and family & 21. Achieve mental health benefits & 33. Increased community pride \\
\hline $\begin{array}{l}\text { 8. Experiencing something new and } \\
\text { different }\end{array}$ & $\begin{array}{l}\text { 22. Achieve physical health benefits } \\
\text { 23. Increase self-confidence }\end{array}$ & $\begin{array}{l}\text { 34. Protection of biological diversity } \\
\text { 35. Protection of drinking water }\end{array}$ \\
\hline 9. Having fun & 24. Improve quality of life & 36. Provision of clean air \\
\hline 10. Challenging oneself & & 37. Provision of green spaces \\
\hline $\begin{array}{l}\text { 11. Learning about nature, culture and } \\
\text { heritage }\end{array}$ & & $\begin{array}{l}\text { 38. Reduction in the cost of health } \\
\text { care }\end{array}$ \\
\hline 12. Reflecting on personal values & & 39. Reduction in climate change \\
\hline
\end{tabular}

Sources: Based on interviews with senior managers of three national park management agencies, with analysis informed by benefits research spanning 20 years including McCool and Reilly (1993), Stein and Lee (1995), Driver (2008), Weber and Anderson (2010), Godbey and Mowen (2011), and Manning (2011).

Table 2. Persuasive Potential of the Communication Intervention(s).

\begin{tabular}{lllll}
\hline Dimension & Vividness & Valence & Quantity & Modality \\
\hline $\begin{array}{l}\text { Description } \\
\text { of Scale }\end{array}$ & 7-point semantic & 7-point semantic & 7-point rating scale & 7-point rating scale \\
& $\begin{array}{l}\text { differential scale }- \text { "The } \\
\text { mental imagery I } \\
\text { experienced was ..." }\end{array}$ & $\begin{array}{l}\text { differential scale - "The } \\
\text { mental imagery I } \\
\text { experienced was ..." }\end{array}$ & $\begin{array}{l}\text { from 1 strongly } \\
\text { disagree to 7 strongly } \\
\text { agree }\end{array}$ & $\begin{array}{l}\text { disagree to 7 strongly } \\
\text { agree }\end{array}$ \\
\hline Items & Vivid - vague & Pleasant - unpleasant & Many images came & I imagined tastes \\
& Clear - unclear & Good - bad & to my mind & I imagined scents \\
& Sharp - dull & Nice - awful & A lot of images came & I imagined sounds \\
& Intense - weak & Likable - not likable & to my mind & I imagined visual \\
& Well-defined - fuzzy & Positive - negative & I experienced very & scenes \\
& & & few images & \\
\hline
\end{tabular}

Note: Scores for the items in each dimension were averaged to create a 1-7 score.

Source: Based on Lee and Gretzel (2012), adapted from Miller, Hadjimarcou, and Miciak (2000). 
Table 3. Respondent Profile.

\begin{tabular}{|c|c|c|c|c|}
\hline \multirow{2}{*}{$\begin{array}{l}\text { STATE } \\
\text { Variable }\end{array}$} & \multicolumn{2}{|c|}{$\begin{array}{l}\text { New South Wales } \\
(n=532)\end{array}$} & \multicolumn{2}{|c|}{$\begin{array}{l}\text { Victoria } \\
(n=521)\end{array}$} \\
\hline & $\%$ & Sample & $\%$ & Sample \\
\hline \multicolumn{5}{|l|}{ AGE } \\
\hline $18-29$ years & $41.3 \%$ & 220 & $39.5 \%$ & 206 \\
\hline $30-49$ years & $20.5 \%$ & 109 & $22.1 \%$ & 115 \\
\hline 50 years + & $38.2 \%$ & 203 & $38.4 \%$ & 200 \\
\hline \multicolumn{5}{|l|}{ GENDER } \\
\hline Male & $49.8 \%$ & 265 & $49.3 \%$ & 257 \\
\hline Female & $50.2 \%$ & 267 & $50.7 \%$ & 264 \\
\hline \multicolumn{5}{|c|}{ PLACE OF RESIDENCE } \\
\hline Urban (state capital) & $58.7 \%$ & 269 & $49.2 \%$ & 227 \\
\hline Regional & $41.3 \%$ & 189 & $50.8 \%$ & 234 \\
\hline \multicolumn{5}{|c|}{ PARK VISITATION IN THE PAST 12 MONTHS } \\
\hline Yes & $77.6 \%$ & 413 & $62.8 \%$ & 327 \\
\hline No & $11.1 \%$ & 59 & $25.3 \%$ & 132 \\
\hline Don’t Know & $11.3 \%$ & 60 & $11.9 \%$ & 62 \\
\hline \multicolumn{5}{|c|}{ FREQUENCY OF PARK VISITATION * } \\
\hline Very frequently & $13.1 \%$ & 54 & $18.7 \%$ & 61 \\
\hline Moderately frequently & $21.1 \%$ & 87 & $27.8 \%$ & 91 \\
\hline Less frequently & $65.8 \%$ & 272 & $53.5 \%$ & 175 \\
\hline
\end{tabular}

$*$ Very frequently $=$ weekly or daily basis; Moderately frequently $=>5$ times a year; Less frequently $=5$ times a year or less. 
Table 4. Victoria - Target Benefits.

\begin{tabular}{|c|c|c|c|c|c|c|c|}
\hline \multirow[b]{2}{*}{ Benefit Items targeted in Parks Victoria video intervention } & \multicolumn{4}{|c|}{$(\mathrm{n}=\mathbf{5 2 1})$} & \multirow{2}{*}{\multicolumn{3}{|c|}{$\begin{array}{l}\text { T-test } \\
\text { (paired) }\end{array}$}} \\
\hline & Pre-Test & & st-Test & & & & \\
\hline Mean level of agreement (1-7 scale) & Mean & SD & Mean & SD & $t=\mathbf{d f}$ & $\begin{array}{c}\text { Sig. } \\
(p=0.05)\end{array}$ & $\begin{array}{c}\text { Effect Size } \\
\text { (Cohen's D) }\end{array}$ \\
\hline Access natural experiences & 5.43 & 1.18 & 5.66 & 1.10 & $t(-5.55)=520$ & 0.00 & -0.24 \\
\hline Improve quality of life & 5.31 & 1.09 & 5.59 & 1.10 & $\mathrm{t}(-7.28)=520$ & 0.00 & -0.32 \\
\hline Achieve mental health benefits & 5.17 & 1.25 & 5.50 & 1.21 & $t(-7.91=520$ & 0.00 & -0.34 \\
\hline Achieve physical health benefits & 5.45 & 1.11 & 5.68 & 1.08 & $t(-6.36)=520$ & 0.00 & -0.27 \\
\hline Increased community wellbeing & 5.17 & 1.17 & 5.50 & 1.13 & $t(-9.46)=520$ & 0.00 & -0.41 \\
\hline Reduction in the cost of healthcare & 4.67 & 1.44 & 5.03 & 1.36 & $\mathrm{~T}(-8.77)=520$ & 0.00 & -0.38 \\
\hline
\end{tabular}

Note: There was little variability in standard error - it ranged from 0.05 to 0.06 .

Table 5. New South Wales - Target Benefits.

\begin{tabular}{|c|c|c|c|c|c|c|c|}
\hline \multirow{2}{*}{$\begin{array}{l}\text { RESIDENTS OF NSW } \\
\text { Benefit Items targeted in NPWS website intervention }\end{array}$} & \multicolumn{4}{|c|}{$(n=532)$} & \multirow[b]{2}{*}{ T-test (paired) } & \multirow[b]{3}{*}{$\begin{array}{c}\text { Sig. } \\
(p=0.05)\end{array}$} & \multirow[b]{3}{*}{$\begin{array}{l}\text { Effect Size } \\
\text { (Cohen's D) }\end{array}$} \\
\hline & \multicolumn{2}{|c|}{ Pre-Test } & \multicolumn{2}{|c|}{ Post-Test } & & & \\
\hline Mean level of agreement (1-7 scale) & Mean & SD & Mean & SD & $\mathbf{t}=\mathbf{d f}$ & & \\
\hline Learn about nature, culture and heritage & 5.34 & 1.16 & 5.62 & 1.12 & $\mathrm{t}(-6.4)=531$ & 0.00 & -0.28 \\
\hline Connect with heritage & 5.08 & 1.19 & 5.45 & 1.15 & $t(-8.63)=531$ & 0.00 & -0.37 \\
\hline Connect with culture & 4.94 & 1.24 & 5.42 & 1.13 & $t(-11.13)=531$ & 0.00 & -0.48 \\
\hline Conservation of culture & 4.96 & 1.24 & 5.38 & 1.22 & $t(-9.66)=531$ & 0.00 & -0.42 \\
\hline Conservation of heritage & 5.02 & 1.20 & 5.44 & 1.78 & $\mathrm{t}(9.77)=531$ & 0.00 & -0.42 \\
\hline
\end{tabular}

Note: There was little variability in standard error - it ranged from 0.05 to 0.06 . 
Table 6. Comparison of Dimensions of Mental Imagery for the Two Interventions.

\begin{tabular}{lll} 
Dimensions of mental imagery & $\begin{array}{l}\text { NPWS Website } \\
(\mathbf{n = 5 3 2})\end{array}$ & $\begin{array}{l}\text { PV Video } \\
(\mathbf{n = 5 2 1})\end{array}$ \\
\hline Mean level of agreement/positivity & Mean & Mean \\
(1-7 scale) & 4.84 & 4.97 \\
Total Quantity scores & 4.42 & 4.66 \\
Total Modality scores & 5.11 & 5.21 \\
Total Vividness scores & 5.71 & 5.80 \\
Total Valence scores & & \\
\hline
\end{tabular}

Note: There was little variability in standard error - it ranged from 0.05 to 0.06 .

Table 7. Perceived Source of Credibility.

\begin{tabular}{|c|c|c|c|c|}
\hline \multirow[b]{2}{*}{ Source of Credibility* } & \multicolumn{2}{|c|}{ Victoria (video) } & \multicolumn{2}{|c|}{ NSW (website) } \\
\hline & Frequency & $\begin{array}{l}\text { Percent } \\
(n=419)\end{array}$ & Frequency & $\begin{array}{l}\text { Percent } \\
(n=480)\end{array}$ \\
\hline $\begin{array}{l}\text { Images of scenery, landscapes, nature (visuals, } \\
\text { pictures/photos) }\end{array}$ & 80 & $19 \%$ & 133 & $28 \%$ \\
\hline $\begin{array}{l}\text { Informative, written text, knowledge, concise } \\
\text { (and for NSW - website design) }\end{array}$ & 33 & $8 \%$ & 74 & $15 \%$ \\
\hline $\begin{array}{l}\text { Parks Victoria / NPWS as a government agency - } \\
\text { logo, signs }\end{array}$ & 12 & $3 \%$ & 58 & $12 \%$ \\
\hline $\begin{array}{l}\text { Park Rangers/staff, park uniforms, university } \\
\text { researchers, other experts }\end{array}$ & 103 & $25 \%$ & $\mathrm{n} / \mathrm{a}$ & - \\
\hline $\begin{array}{l}\text { People in parks, real people, everyday people } \\
\text { doing activities }\end{array}$ & 31 & $7 \%$ & $\mathrm{n} / \mathrm{a}$ & - \\
\hline
\end{tabular}

*These categories reflect responses that were most frequently mentioned in either one or both states. There were other responses such as "yes", "all/everything", "most of it" and "credible based on my personal experience of visiting parks" that were frequently mentioned but have not been included here because they were deemed as not providing insight into the source of perceived credibility. 